OPEN ACCESS

Edited by:

Hai Chao Chen,

Qingdao University, China

Reviewed by:

Chengzhen Wei,

Anyang Normal University, China

Kaifu Huo,

Huazhong University of Science and

Technology, China

${ }^{*}$ Correspondence:

Tingting Luo

luotingting27@whut.edu.cn

Xu Chen

X.Chen@fkf.mpg.de

Hanbin Wang

123272314@qq.com

tThese authors have contributed equally to this work

Specialty section: This article was submitted to

Electrochemistry,

a section of the journa

Frontiers in Chemistry

Received: 20 May 2020

Accepted: 26 June 2020

Published: 15 September 2020

Citation:

Chen S, Yang G, Zhao X, Wang N, Luo $T$, Chen $X, W u T$, Jiang $S$, van Aken PA, Qu S, Li T, Du L, Zhang J, Wang $H$ and Wang $H$ (2020) Hollow Mesoporous Carbon Spheres for High

Performance Symmetrical and

Aqueous Zinc-lon Hybrid

Supercapacitor. Front. Chem. 8:663.

doi: $10.3389 /$ fchem.2020.00663

\section{Hollow Mesoporous Carbon Spheres for High Performance Symmetrical and Aqueous Zinc-Ion Hybrid Supercapacitor}

\author{
Sihan Chen ${ }^{1+}$, Gaoqi Yang ${ }^{1 \dagger}$, Xiaojuan Zhao ${ }^{1+}$, Nengze Wang ${ }^{1}$, Tingting Luo ${ }^{2 *}$, Xu Chen ${ }^{3 *}$, \\ Tianci Wu ${ }^{1}$, Shijie Jiang ${ }^{1}$, Peter A. van Aken ${ }^{3}$, Shile $Q u^{1}$, Tao Li ${ }^{1}$, Liang $D u^{1}$, Jun Zhang ${ }^{1}$, \\ Hanbin Wang ${ }^{1 *}$ and Hao Wang ${ }^{1}$ \\ ${ }^{1}$ Hubei Key Laboratory of Ferro and Piezoelectric Materials and Devices, Faculty of Physics and Electronic Science, Hubei \\ University, Wuhan, China, ${ }^{2}$ State Key Laboratory of Advanced Technology for Materials Synthesis and Processing, Wuhan \\ University of Technology, Wuhan, China, ${ }^{3}$ Stuttgart Center for Electron Microscopy, Max Planck Institute for Solid State \\ Research, Stuttgart, Germany
}

Zinc-ion hybrid supercapacitors are a promising energy storage device as they simultaneously combine the high capacity of batteries and the high power of supercapacitors. However, the practical application of Zinc-ion hybrid supercapacitors is hindered by insufficient energy density and poor rate performance. In this study, a symmetrical zinc-ion hybrid supercapacitor device was constructed with hollow mesoporous-carbon nanospheres as electrode materials, and aqueous $\mathrm{ZnSO}_{4}$ adopted as an electrolyte. Benefiting from the mesoporous structure and high specific area $\left(800 \mathrm{~m}^{2} / \mathrm{g}\right)$ of the hollow carbon nanospheres, fast capacitor-type ion adsorption/de-adsorption on both the cathode and the anode can be achieved, as well as additional battery-type $\mathrm{Zn} / \mathrm{Zn}^{2+}$ electroplating/stripping on the anode. This device thus demonstrates outstanding electrochemical performance, with high capacity (212.1 $\mathrm{F} / \mathrm{g}$ at $0.2 \mathrm{~A} / \mathrm{g})$, a high energy density $(75.4 \mathrm{Wh} / \mathrm{kg}$ at $0.16 \mathrm{~kW} / \mathrm{kg})$, a good rate performance (34.2 Wh/kg energy density maintained at a high power density of 16.0 $\mathrm{kW} / \mathrm{kg}$ ) and excellent cycling stability with $99.4 \%$ capacitance retention after 2,500 cycles at $2 \mathrm{~A} / \mathrm{g}$. The engineering of this new configuration provides an extremely safe, high-rate, and durable energy-storage device.

Keywords: mesoporous carbon, zinc ion battery, supercapacitor, hollow sphere, energy storage

\section{INTRODUCTION}

With the continuous development of electric vehicles, smart electric grids, and miniaturized electronics, it is important to develop high-performance electrochemical energy storage systems (Sun et al., 2018; Zhang et al., 2019). The construction of better energy storage devices relies not only on the structure design of electrode materials, but also more crucially, it depends on the engineering of the device configuration (Zhang et al., 2014; Zuo et al., 2017; Chen et al., 2019b).

A hybrid battery-supercapacitor device, which is typically constructed with a high capacity battery-type electrode and a high rate capacitor-type electrode, has proven to be an effective way of simultaneously combining the merits of batteries and supercapacitors (Gan et al., 2019; Wang et al., 2019; Tan et al., 2020). Currently, existing electrolytes include organic, ionic liquid, and aqueous solutions, among which the later has advantages of high 
ionic conductivity, low cost, inflammability, and it is environmentally benign (Chen et al., 2014; Wan et al., 2018). Energy storage systems based on monovalent cations $\left(\mathrm{Li}^{+}, \mathrm{Na}^{+}\right.$, and $\mathrm{K}^{+}$) have been widely investigated and significant progress has been achieved (Shen and Yu, 2017; Shen et al., 2018, 2019). Multivalent cations $\left(\mathrm{Mg}^{2+}, \mathrm{Zn}^{2+}, \mathrm{Ni}^{2+}, \mathrm{Ca}^{2+}\right.$, and $\left.\mathrm{Al}^{3+}\right)$ are becoming more attractive, since one mole reacted multivalent ions can provide double or triple the number of electrons as compared to monovalent cations (Bitenc and Dominko, 2018; Cui et al., 2018; Dong et al., 2018; Liu et al., 2019a,b; Zhan et al., 2020). Moreover, multivalent cation-based devices are also more air-resistant and thus more applicable in practice (Sun et al., 2020).

Aqueous zinc-ion hybrid supercapacitors (ZHSs) have recently emerged as promising energy storage devices, due to the intrinsic advantages of the zinc element, such as a high capacity of $820 \mathrm{mAh} / \mathrm{g}$ in theory, low redox potential of $-0.76 \mathrm{~V}$ vs. a standard hydrogen electrode (Ma et al., 2018; Chen et al., 2019a; Yu et al., 2019). For instance, Ma et al. (2019) have developed a ZHS with a $\gamma$-phase $\mathrm{MnO}_{2}$ nanorods as a cathode and activated carbon particles as an anode, which demonstrated a high specific capacity of $54.1 \mathrm{mAh} / \mathrm{g}(34.8 \mathrm{Wh} / \mathrm{kg})$ at $0.1 \mathrm{~A} / \mathrm{g}$ current density. After 1,000 charge/discharge cycles, $80 \%$ of the device capacity is preserved. Dong et al. have constructed a novel ZHS device using $\mathrm{Zn}$ metal and activated carbon as an anode and a cathode, respectively. This device revealed a high capacity of $121 \mathrm{mAh} / \mathrm{g}$ $(84 \mathrm{Wh} / \mathrm{kg}$ ) at $0.1 \mathrm{~A} / \mathrm{g}$ current density, meanwhile, a high cycling stability of $91 \%$ capacity retention after $10 \mathrm{k}$ charge/discharge cycles at $1 \mathrm{~A} / \mathrm{g}$ (Dong et al., 2018). At the same time, Wang et al. made a similar ZHS device using Zn-metal as anode and activated-carbon as a cathode with a capacity of $170 \mathrm{~F} / \mathrm{g}$ at 0.1 $\mathrm{A} / \mathrm{g}$, an energy density of $52.7 \mathrm{Wh} / \mathrm{kg}$ at $1.7 \mathrm{~kW} / \mathrm{kg}$ and a $91 \%$ capacitance retention after $20 \mathrm{k}$ cycles at $2 \mathrm{~A} / \mathrm{g}$ (Wang et al., 2018).

In this study, a symmetrical zinc-ion hybrid supercapacitor system was constructed using mesoporous-carbon nanospheres with a hollow structure as both anode and cathode materials, as well as aqueous $\mathrm{ZnSO}_{4}$, which was adopted as an electrolyte. The device chemistry is based on the adsorption or de-adsorption of anions onto mesoporous carbon as the cathode reaction, and electroplating or stripping of $\mathrm{Zn} / \mathrm{Zn}^{2+}$ as the anode reaction. The capacity of the symmetry zinc-ion hybrid supercapacitor device reaches $212.1 \mathrm{~F} / \mathrm{g}$ at a current density of $0.2 \mathrm{~A} / \mathrm{g}$, corresponding to an energy density of $75.4 \mathrm{Wh} / \mathrm{kg}$ at a power density of 0.16 $\mathrm{kW} / \mathrm{kg}$. When increasing the current density to $20 \mathrm{~A} / \mathrm{g}, 34.2$ $\mathrm{Wh} / \mathrm{kg}$ energy density is maintained at a high power density of $16.0 \mathrm{~kW} / \mathrm{kg}$, which yields a good rate capability. Te device exhibits excellent cycling stability with $99.4 \%$ capacity retention over 2,500 cycles.

\section{EXPERIMENTAL SECTIONS}

\section{Synthesis of Resorcinol-Formaldehyde (RF) Coated $\mathrm{SiO}_{2}\left(\mathrm{SiO}_{2} @ \mathrm{RF}\right)$ Spheres}

$\mathrm{SiO}_{2} @ \mathrm{RF}$ spheres were one-step synthesized by a modified liquid deposition method (Fang et al., 2014). In a typical process, $3.46 \mathrm{~mL}$ of tetrapropoxysilane (TPOS) was dissolved into a mixture solution of ethanol $(70 \mathrm{~mL})$, deionized water $(10 \mathrm{~mL})$, and ammonia solution $(3 \mathrm{~mL})$. Then $0.4 \mathrm{~g}$ of resorcinol and $0.56 \mathrm{~mL}$ of formaldehyde were sequentially added into the solution, and then magnetically stirred at $35^{\circ} \mathrm{C}$ for $24 \mathrm{~h} . \mathrm{SiO}_{2} @ \mathrm{RF}$ spheres were separated from the obtained suspension by suction filtration, washed with water/ethanol, and dried at atmosphere.

\section{Synthesis of Hollow Mesoporous-Carbon Spheres (HMCS)}

The $\mathrm{SiO}_{2} @ \mathrm{C}$ nanospheres were obtained by carbonization of $\mathrm{SiO}_{2} @ \mathrm{RF}$ at $700^{\circ} \mathrm{C}$ for $5 \mathrm{~h}$ under a $\mathrm{N}_{2}$ atmosphere, with a heating rate of $2^{\circ} \mathrm{C} / \mathrm{min}$. After washing with $4 \mathrm{M} \mathrm{NaOH}$ solution, the as-synthesized core-shell $\mathrm{SiO}_{2} @ \mathrm{C}$ spheres were converted into the HMCS.

\section{Materials Characterization}

$\mathrm{X}$-ray powder diffraction (XRD) was performed with a Bruker D8 diffractometer with $\mathrm{Cu} \mathrm{K} \alpha$ radiation. The size and morphology of as-synthesized materials were characterized by Scanning Electron Microscope (SEM, JSM7100F JEOL). Transmission electron microscopy (TEM), high-resolution TEM (HRTEM), and highangle annular dark-field (HAADF) scanning transmission electron microscopy (STEM) analysis were performed using a JEOL ARM 200F microscope equipped with a cold field emission electron source and an image Cs corrector (CEOS $\mathrm{GmbH}$ ) operated at $200 \mathrm{kV}$. The specific surface area of HMCS was measured using a Micromeritics ASAP2020 and calculated using the Brunauer-Emmett-Teller (BET) method. $\mathrm{X}$-ray photoelectron spectroscopy (XPS) measurements were carried out using a Thermo Fisher Scientific Escalab 250Xi spectrometer with $\mathrm{Al} \mathrm{K} \alpha$ radiation.

\section{Electrochemical Measurements}

Electrochemical measurements were performed via an electrochemical workstation of CHI760E. To prepare the electrode materials, carbon nanospheres, and acetylene black were firstly uniformly dispersed in a poly-tetra-fluoroethylene (PTFE) suspension (60 wt\%) into a slurry under ultrasonication for $1 \mathrm{~h}$. The ratio of electroactive materials, binder, and conducting materials was controlled to be $8: 1: 1$. Then, the slurry was coated on a nickel foam disc with a diameter of $12 \mathrm{~mm}$, followed by drying at $70^{\circ} \mathrm{C}$ under vacuum for $12 \mathrm{~h}$. After that, the nickel foam with electroactive materials was pressed into a plate under $10 \mathrm{MPa}$. The loading of the electroactive materials was controlled to be $3-4 \mathrm{mg} / \mathrm{cm}^{2}$ for each electrode. Symmetric hybrid supercapacitor devices were assembled with a standard coin battery set-up, with the as-prepared electrodes described above, as both anode and cathode materials. Three different electrolytes were adopted to study the energy-storage mechanism and to optimize the electrochemical performance, including $2 \mathrm{M}$ $\mathrm{ZnSO}_{4}, 1 \mathrm{M} \mathrm{Na}_{2} \mathrm{SO}_{4}$, and their combination. Cyclic voltammetry (CV) and galvanostatic charge/discharge (GCD) measurements were applied to characterize the electrochemical performance of the constructed devices. 


\section{RESULTS AND DISCUSSIONS}

The preparation process of HMCS is illustrated in Figure 1A. Firstly, core-shell $\mathrm{SiO}_{2} @ \mathrm{RF}$ nanospheres are synthesized as an intermediate by a liquid deposition method containing TPOS, formaldehyde, and resorcinol. Then, $\mathrm{SiO}_{2} @ \mathrm{RF}$ is carbonized into $\mathrm{SiO}_{2} @ \mathrm{C}$ at $700^{\circ} \mathrm{C}$ under $\mathrm{N}_{2}$ for $5 \mathrm{~h}$, and HMCS is obtained after removing $\mathrm{SiO}_{2}$ by $\mathrm{NaOH}$ etching. The SEM images of $\mathrm{SiO}_{2} @ \mathrm{RF}$ demonstrate (Figures 1B,C) that the product has a spherical shape with a high uniformity of monodisperse spheres, with an average diameter of about $350 \mathrm{~nm}$. A layer of mesoporous silica formed on the surface of $\mathrm{SiO}_{2} @ R F$. Figures 1D,E are SEM images of $\mathrm{SiO}_{2} @ \mathrm{C}$ nanospheres, revealing that the morphology of $\mathrm{SiO}_{2} @ \mathrm{RF}$ is well-maintained after annealing at $700^{\circ} \mathrm{C}$, with the carbonization process under precise control. Figures 1F,G show a uniform and spherical shape of as-synthesized HMCS, but their size decreases to about $\sim 310 \mathrm{~nm}$ in diameter. The surface roughness increases after alkaline etching of $\mathrm{SiO}_{2} @ \mathrm{C}$. From SEM analysis, HMCS has a relatively rough surface, which can provide more active sites to modify functional groups on their surface, effectively avoiding the phenomenon of pore blockage. This structure is therefore very advantageous for the rapid adsorption/desorption of electrolyte ions.

STEM techniques were used to characterize the inner structure and elemental distribution of HMCS particles. A lowmagnification STEM-HAADF image (Figure 1H) further proves that the HMCS particles are uniform, non-agglomerated and possess an obvious hollow structure with an inner diameter of $\sim 235 \mathrm{~mm}$ and an outer diameter of $\sim 310 \mathrm{~nm}$. Interpenetrating channels of the HMCS surface are observed in a magnified STEM-HAADF image (Figure 1I). The element carbon is uniformly distributed throughout the sphere as presented in the STEM-EELS image (Figure 1J). The surface composition of the hollow mesoporous carbon spheres was analyzed by XPS (Figure S1). The C-1s spectrum has been deconvoluted into three peaks at 284.6, 286.1, and $288.3 \mathrm{eV}$, which are assigned to $\mathrm{C}-\mathrm{C}, \mathrm{C}-\mathrm{O}$, and $\mathrm{C}=\mathrm{O}$, respectively, based on XPS spectrum analysis. These results confirm the complete carbonization of $\mathrm{SiO}_{2} @ \mathrm{RF}$, and $\mathrm{SiO}_{2}$ removal by $\mathrm{NaOH}$ afterward. The hollow and porous surface structures of carbon nanospheres provide ultrahigh porosity and excellent performance of molecular sieving, which makes it possible for them to interact with atoms, molecules, and even larger objects, not only on their outer surface but also throughout the entire material, which can benefit its electrochemical performance as an electroactive material.

Figure 2A shows $\mathrm{X}$-ray diffraction patterns of the reaction intermediates during synthesis and the HMCS spheres. The XRD patterns of $\mathrm{SiO}_{2} @ \mathrm{RF}, \mathrm{SiO}_{2} @ \mathrm{C}$, and HMCS show all an obvious diffraction peak at around $24^{\circ}$. The $24^{\circ}$ diffraction peak

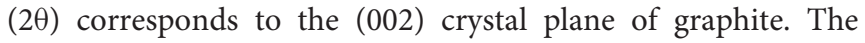
characteristic diffraction peak intensity of HMCS increases and the peak is sharper, indicating that the crystallinity has increased, and the conductivity has improved after high-temperature calcination. In addition, a broad diffraction peak appeared near $43^{\circ}$ in the diffraction pattern of HMCS, which corresponds to the (101) crystal plane of graphite, illustrating that the asprepared carbon material has crystalline graphite characteristics.
No further diffraction maxima apart from the two mentioned before were observed.

Figure 2B shows the $\mathrm{N}_{2}$ adsorption-desorption isotherm of the as-synthesized HMCS. A typical Type-IV isotherm can be seen with an H3-type hysteresis loop at the relative pressure of $\mathrm{P} / \mathrm{P}_{0}>0.7$, according to the IUPAC classification, which indicates the mesoporous-rich textural and slit-pore properties of the carbon nanospheres. Pore size distribution is then extracted from the isotherm curve, as shown in Figure 2C, which shows a mean pore diameter of about $10 \mathrm{~nm}$. The specific area of carbon spheres can also be calculated with a value of $800 \mathrm{~m}^{2} / \mathrm{g}$, which is much higher than the $427 \mathrm{~m}^{2} / \mathrm{g}$ of mesoporous carbon spheres reported by the Zhao group (Yan et al., 2007). This mesoporous structure and slit pore surface of the carbon spheres are beneficial for ion diffusion in the electrolyte, which improves the electrochemical performance of the electrode materials.

To construct efficient zinc-ion hybrid supercapacitors, assynthesized HMCS particles are adopted as electroactive materials for both the anode and cathode, with three different electrolytes of $1 \mathrm{M} \mathrm{Na}_{2} \mathrm{SO}_{4}, 2 \mathrm{M} \mathrm{ZnSO}_{4}$, and their mixture. Figure 3A shows the $\mathrm{CV}$ curves of these three devices at a $5 \mathrm{mV} / \mathrm{s}$ scan rate, which can be used to qualitatively reveal their specific capacitance. The larger the specific area of the closed CV pattern, the larger the specific capacitance. For the hybrid supercapacitor device consisting of a mixture of the electrolytes $\mathrm{Na}_{2} \mathrm{SO}_{4}$ and $\mathrm{ZnSO}_{4}$, its specific capacitance is larger than of the supercapacitor device with a $\mathrm{ZnSO}_{4}$ electrolyte (zinc-ion supercapacitor) or with a $\mathrm{Na}_{2} \mathrm{SO}_{4}$ electrolyte (sodium-ion supercapacitor), which is the smallest. We speculate that this is due to a higher efficiency of divalent $\mathrm{Zn}^{2+}$ compared to monovalent $\mathrm{Na}^{+}$, while the charge storage mechanism of a device containing a $\mathrm{Zn}^{2+}$ electrolyte is based on a $\mathrm{Zn}^{2+}$ hybrid supercapacitor. The specific capacitance can be quantified by a CV curve based on equation 1 (Parveen et al., 2016):

$$
C=\frac{\int I d t}{m d V}
$$

where $C, m, V, I, d t$ are the specific capacitance $(\mathrm{F} / \mathrm{g})$, the mass (g) of the electroactive material, the working voltage window $(\mathrm{V})$, the current $(\mathrm{A})$, and the time differential, respectively. The hybrid supercapacitor device has a specific capacitance of $226 \mathrm{~F} / \mathrm{g}$, which is larger than the zinc-ion supercapacitor (209.5 F/g) and higher than the sodium-ion supercapacitor $(139.1 \mathrm{~F} / \mathrm{g})$.

Figure 3B shows the constant current charge-discharge curves obtained for these three devices at $0.5 \mathrm{~A} / \mathrm{g}$ current density within the potential arrange of $0-1.6 \mathrm{~V}$. We calculate the specific capacitance according to equation 2 (Meng et al., 2014; Wei et al., 2018c):

$$
C=\frac{I \Delta t}{m \Delta V}
$$

where $\Delta V$ and $\Delta t$ are the working potential window $(\mathrm{V})$ and the discharge time (s). In this case, the specific capacitance $C$ is directly proportional to the discharge time of $\Delta t . \mathrm{I} / \mathrm{m}$ is $0.5 \mathrm{~A} / \mathrm{g}$ and $\Delta V$ is $1.6 \mathrm{~V}$ in Figure $3 \mathbf{B}$, meaning that for the comparison of the specific capacitance, one only needs to 

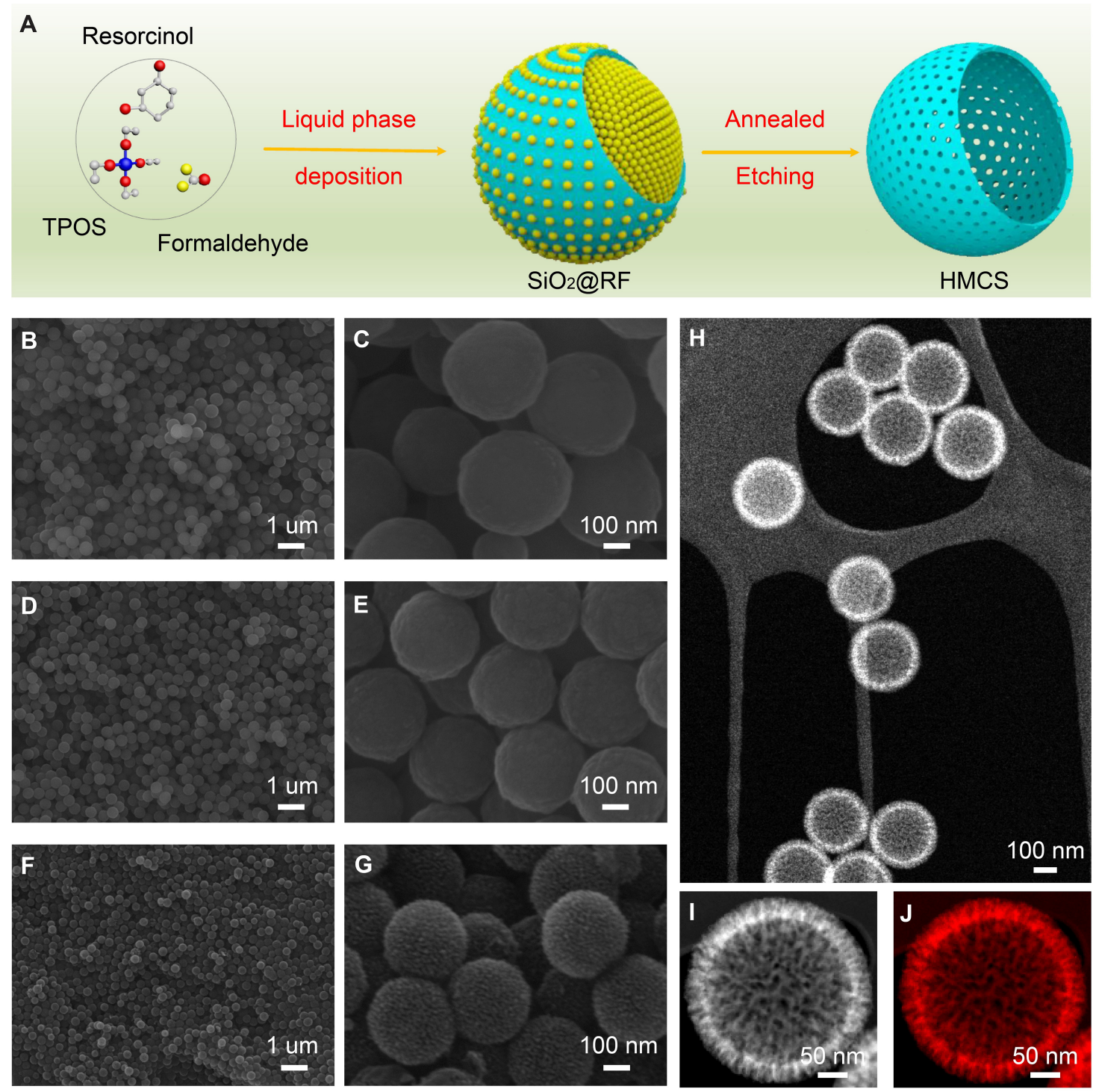

FIGURE 1 | (A) Illustration of the fabrication processes of hollow mesoporous carbon spheres. Low- and high-magnification SEM images (B,C) of resorcinol-formaldehyde-coated $\mathrm{SiO}_{2}$ nanospheres intermediates, (D,E) carbon-coated $\mathrm{SiO}_{2}$ intermediates after carbonizing the organic surface, and (F,G) carbon nanospheres, respectively. (H) HAADF image of as-synthesized carbon nanospheres, which shows obvious hollow spherical structures. (I) A magnified STEM image of one single carbon sphere with a porous surface and $(\mathbf{J})$ C-K edge elemental mapping.

assess the size of $\Delta t$. The relationship between the specific capacitances can be obtained by a hybrid supercapacitor (190.6 $\mathrm{F} / \mathrm{g})>$ zinc-ion supercapacitor $(176.8 \mathrm{~F} / \mathrm{g})>$ sodium-ion supercapacitor $(110.3 \mathrm{~F} / \mathrm{g})$. To further characterize the energy storage performance of this hybrid supercapacitor device, we carried out rate performance measurements with different scan rates of $\mathrm{CV}$ (Figures 3C,D) and with different current densities of GCD (Figure 3E). When the scan rate increases from 5 to $100 \mathrm{mV} / \mathrm{s}$, the shape of the $\mathrm{CV}$ curve shows minor distortion which indicates the good rate performance of the device.

The calculated specific capacitance at different current densities is summarized in Figure 3F. At $0.2 \mathrm{~A} / \mathrm{g}, 212.5$
F/g specific capacitance can be achieved for the hybrid supercapacitor, 207.0 F/g for the zinc-ion supercapacitor, and $130.5 \mathrm{~F} / \mathrm{g}$ for the sodium-ion supercapacitor. When increasing the current density to $20 \mathrm{~A} / \mathrm{g}, 100 \mathrm{~F} / \mathrm{g}$ specific capacitance is maintained for the hybrid supercapacitor, and $87.5 \mathrm{~F} / \mathrm{g}$ and $75.0 \mathrm{~F} / \mathrm{g}$ for the zinc-ion/sodium-ion supercapacitors, respectively. The charge transfer and diffusion impedance of the hybrid supercapacitor device is smaller than that of the zinc/sodium-ion supercapacitor, indicating that the hybrid supercapacitor device has improved electronic and ionic conductivity (Figure S2).

Two key parameters of electrochemical energy storage devices, energy density and power density, can be calculated using the 

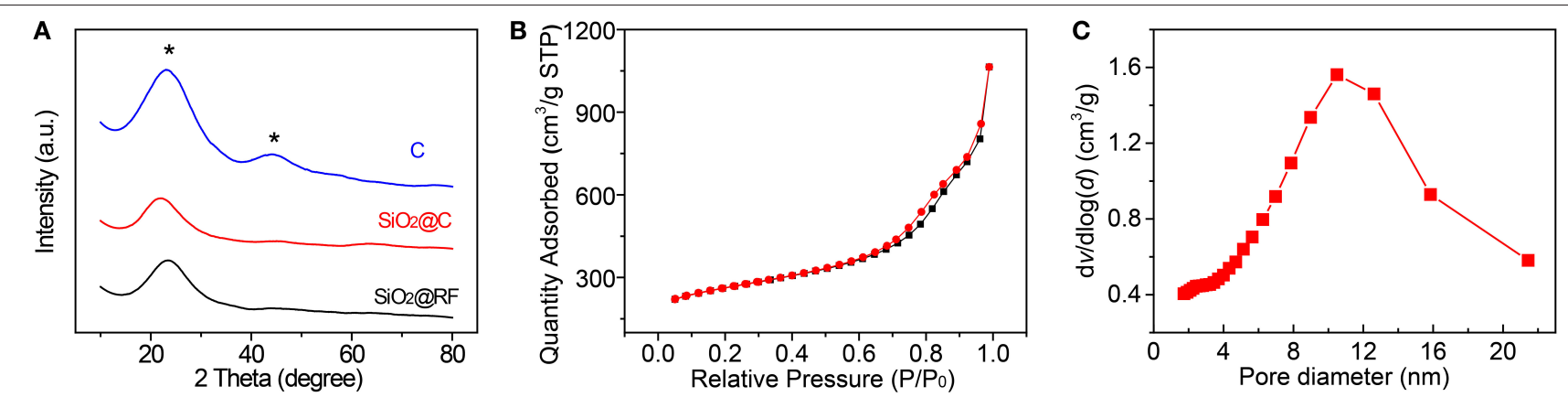

FIGURE 2 | (A) The XRD spectra of $\mathrm{SiO}_{2} @ \mathrm{RF}, \mathrm{SiO}_{2} @ \mathrm{C}$, and carbon nanospheres. (B) $\mathrm{N}_{2}$ adsorption-desorption isotherms and (C) pore size distribution of carbon nanospheres. The star means diffraction peaks of Carbon.

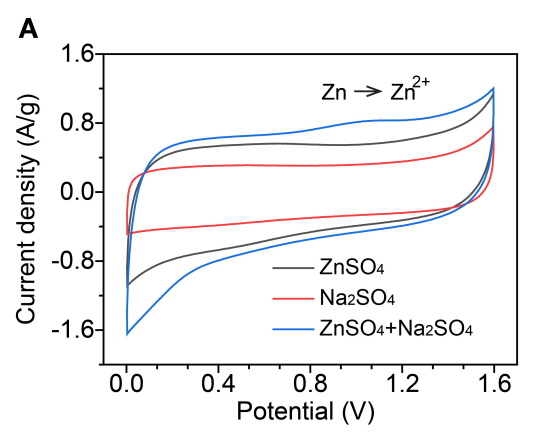

D

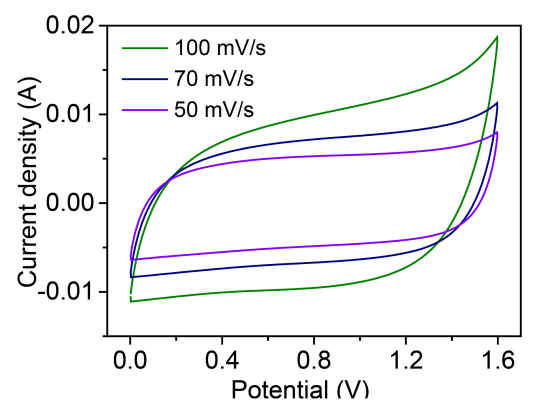

$F$

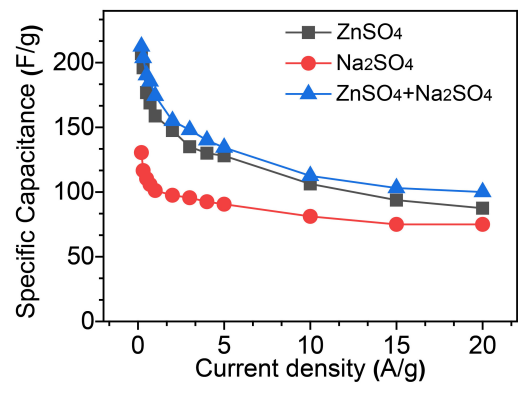

B

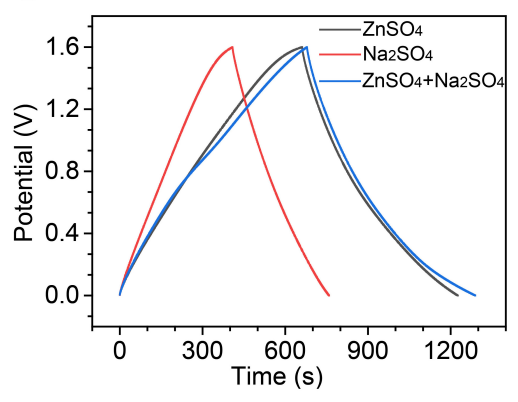

E

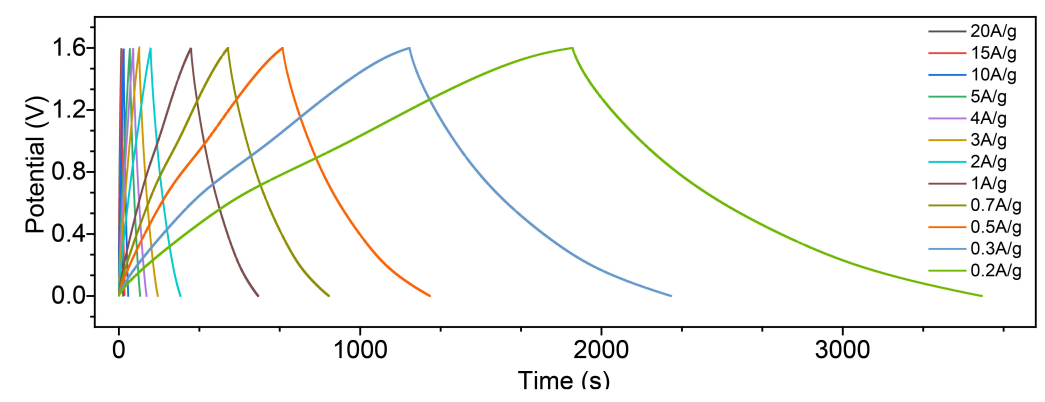

G

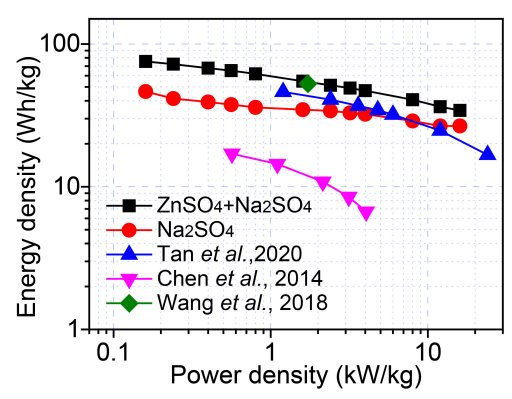

C

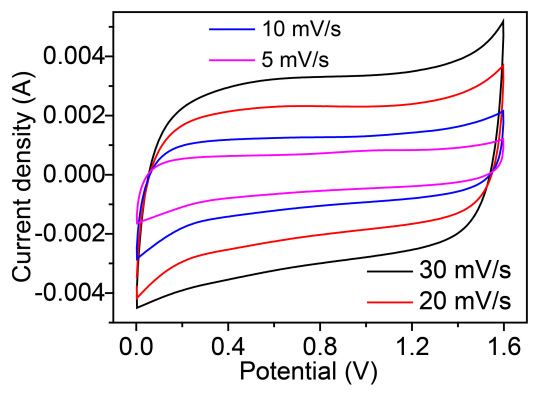

H

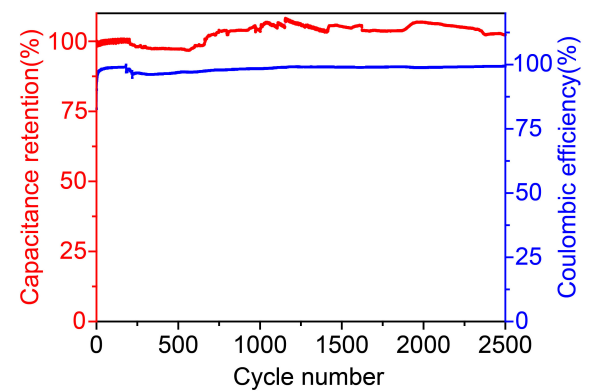

FIGURE 3 | Electrochemical performance of symmetric electrochemical energy storage devices, constructed by as-synthesized HMCS as electroactive materials and three different electrolytes, $1 \mathrm{M} \mathrm{Na}_{2} \mathrm{SO}_{4}, 2 \mathrm{M} \mathrm{ZnSO}$, and their mixture. (A) CV curves of these three devices at $5 \mathrm{mV} / \mathrm{s}$. (B) Charge-discharge curves at $0.5 \mathrm{~A} / \mathrm{g}$. (C,D) CV curves and (E) charge-discharge curves at different scan rates or current densities, respectively. (F) The calculated specific capacities at different current densities. (G) Ragone plots of the electrochemical energy-storage devices and compared to previously reported results (Chen et al., 2014; Wang et al., 2018; Tan et al., 2020). (H) The cyclic stability and columbic efficiency of the devices. 
following equations (Chen et al., 2014; Wei et al., 2018a,b):

$$
\begin{aligned}
& E=\frac{1}{2} C V^{2} \\
& P=\frac{E}{\Delta t}
\end{aligned}
$$

where $E$ is energy density with a unit of $\mathrm{Wh} / \mathrm{kg}$ and $P$ is power density with a unit of $\mathrm{kW} / \mathrm{kg}$, which were calculated and summarized in the Ragone plot of Figure 3G. Our hybrid supercapacitor device shows an $E$ of $75.4 \mathrm{Wh} / \mathrm{kg}$ at 0.16 $\mathrm{kW} / \mathrm{kg}$, which is better than the previously reported zincion supercapacitors and other electrochemical energy storage devices. An energy density of $34.2 \mathrm{Wh} / \mathrm{kg}$ is maintained when the power density is increased to $16.0 \mathrm{~kW} / \mathrm{kg}$. For the device using $\mathrm{ZnSO}_{4}$ as an electrolyte, its energy density is $73.6 \mathrm{Wh} / \mathrm{kg}$ at $0.16 \mathrm{~kW} / \mathrm{kg}$, and $31.1 \mathrm{Wh} / \mathrm{kg}$ at $16.0 \mathrm{~kW} / \mathrm{kg}$. In the device using the $\mathrm{Na}_{2} \mathrm{SO}_{4}$ electrolyte, energy density is $46.4 \mathrm{Wh} / \mathrm{kg}$ at $0.16 \mathrm{~kW} / \mathrm{kg}$, and $26.7 \mathrm{Wh} / \mathrm{kg}$ at $16.0 \mathrm{~kW} / \mathrm{kg}$. Figure $3 \mathrm{H}$ is a comparison chart of the cycle-specific relative capacity of the zinc-ion hybrid supercapacitor with a voltage window from 0 to $1.6 \mathrm{~V}$. The coulombic efficiency of the zinc-ion hybrid supercapacitor reported in this article is close to $100 \%$ during the cycling.

The proposed hybrid energy storage device integrates a series of advantages, such as high capacity and energy density, good rate performance, and cycle stability. In addition, the application of non-toxic electrode materials and aqueous electrolytes means that this new system ensures a high degree of safety in terms of
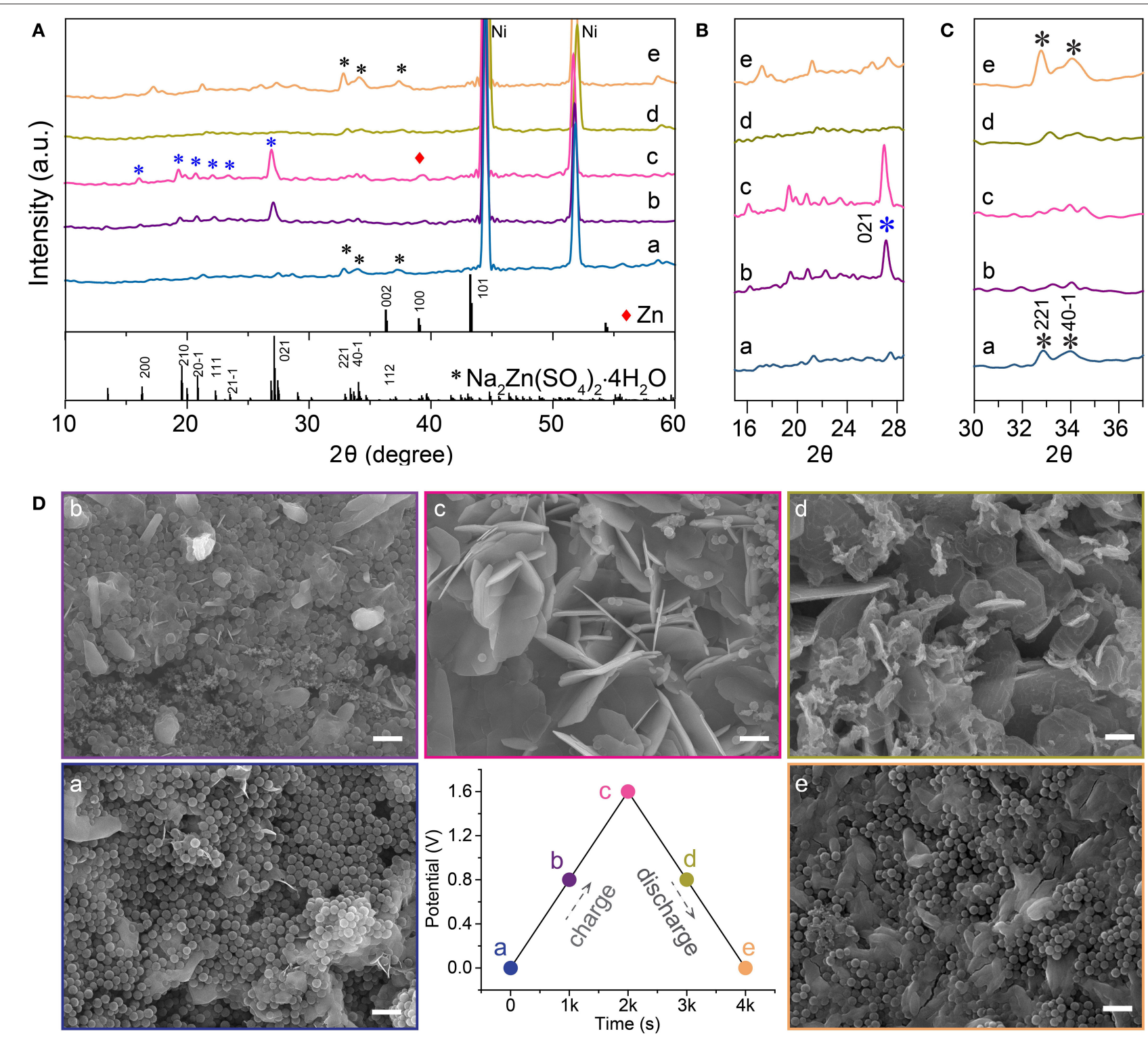

FIGURE 4 | Charge storage mechanism study of zinc-ion hybrid supercapacitors. (A-C) XRD spectra of the anode materials at different charge-discharge states. (D) $\mathrm{SEM}$ images of the anode materials at different charge/discharge states, the scale bars are $1 \mu \mathrm{m}$. The star is highligh of the diffraction pattern of Na2Zn(SO4)2 $4 \mathrm{H} 2 \mathrm{O}$. 


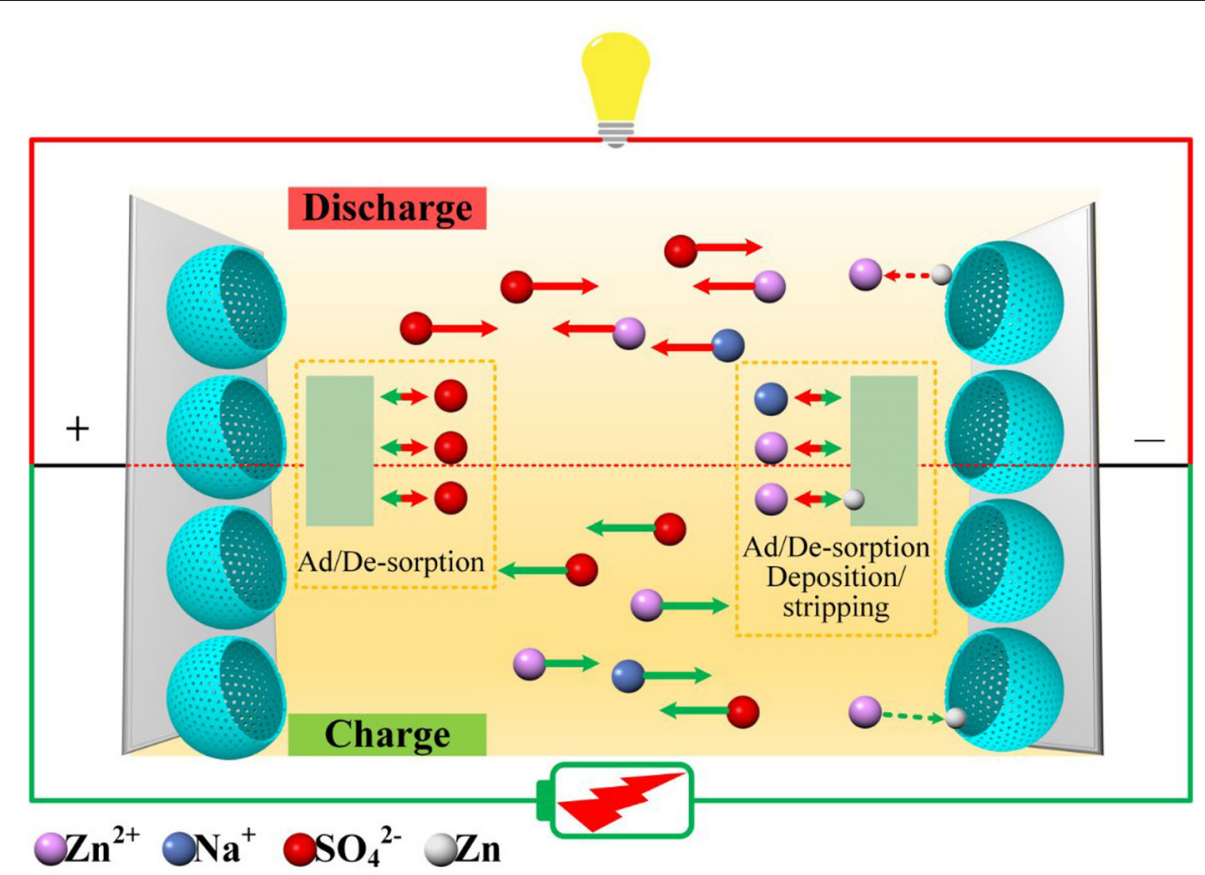

FIGURE 5 | Schematic illustration of the as-proposed device and its working mechanism.

human health and the ecological environment. In summary, we propose HMCS electroactive materials with a Zinc-containing electrolyte as suitable for safe, high-rate, and ultra-long-life rechargeable energy storage.

In order to elucidate the charge storage mechanisms of the symmetry zinc-ion hybrid supercapacitor, with HMCS electroactive materials and electrolytes containing $\mathrm{ZnSO}_{4}$ and/or $\mathrm{Na}_{2} \mathrm{SO}_{4}$, we performed quasi in situ XRD and SEM characterizations of the anode materials at different chargedischarge states, as shown in Figure 4. The charge of the device started at a voltage of 0 , followed by being charged to $0.8 \mathrm{~V}$ and then $1.6 \mathrm{~V}$. After that, the device was discharged to $0.8 \mathrm{~V}$ and finally to $0 \mathrm{~V}$.

XRD spectra of the device at various states of charge and discharge is shown in Figure 4A. Peaks at $16.3^{\circ}, 19.6^{\circ}, 20.9^{\circ}$, $22.3^{\circ}, 23.5^{\circ}, 27.1^{\circ}, 33.4^{\circ}, 34.1^{\circ}$, and $37.1^{\circ}$ for $2 \theta$ match well

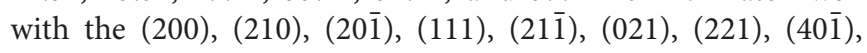
and (112) crystal planes of $\mathrm{Na}_{2} \mathrm{Zn}\left(\mathrm{SO}_{4}\right)_{2} \cdot 4 \mathrm{H}_{2} \mathrm{O}$ (PDF No. $51-$ 1557), respectively. The formation of $\mathrm{Na}_{2} \mathrm{Zn}\left(\mathrm{SO}_{4}\right)_{2} \cdot 4 \mathrm{H}_{2} \mathrm{O}$ can be described by equation 5 and its crystallinity is mainly related to the electro-adsorption of $\mathrm{Zn}^{2+}$ in the anode. As the charging advances, the diffraction intensities of the (221), (401), and (112) crystal planes decrease, accompanied by an intensity increase of the (200), (210), (201) $),(111),(21 \overline{1}),(021)$ reflections, where the (021) reflection in particular, indicates a change of the crystallinity of $\mathrm{Na}_{2} \mathrm{Zn}\left(\mathrm{SO}_{4}\right)_{2} \cdot 4 \mathrm{H}_{2} \mathrm{O}$. In the fully charged state, another diffraction peak at $39.2^{\circ}$ can be assigned to the (100) crystal plane of metallic Zn, which demonstrates that a Faradaic reaction following equation 6 takes place at the anode, which is consistent with the occurrence of redox peaks in the $\mathrm{CV}$ curve in Figure 3A. As the discharge process proceeds in turn, the (021) peak gradually disappears, accompanied by an intensity recovery of the (221), (401), and (112) reflections, which can be clearly distinguished from Figures 4B,C. These results indicate that reverse $\mathrm{Zn}$ plating/stripping took place on the HMOS anode, as well as $\mathrm{Zn}^{2+}$ adsorption/desorption. The SEM images in Figure $4 \mathrm{D}$ indicate that the amount of $\mathrm{Na}_{2} \mathrm{Zn}\left(\mathrm{SO}_{4}\right)_{2} \cdot 4 \mathrm{H}_{2} \mathrm{O}$ nanosheets increase along the charging process from $\mathrm{A}$ to $\mathrm{C}$, and reversely degrade as the discharge process from $\mathrm{C}$ to $\mathrm{E}$. Recharging the device to $1.6 \mathrm{~V}$ after $e$, the anode was fully covered with nanosheets like $\mathrm{Na}_{2} \mathrm{Zn}\left(\mathrm{SO}_{4}\right)_{2} \cdot 4 \mathrm{H}_{2} \mathrm{O}$ (Figure S3). The above quasi in situ $\mathrm{XRD}$ and SEM results prove the excellent cycling stability of $\mathrm{Zn}$-ion hybrid supercapacitors, with its working mechanisms shown in Figure 5 (Dong et al., 2018; Yu et al., 2020).

$$
\begin{aligned}
& 2 \mathrm{Na}^{+}+\mathrm{Zn}^{2+}+2 \mathrm{SO}_{4}^{2-}+4 \mathrm{H}_{2} \mathrm{O} \rightarrow \mathrm{Na}_{2} \mathrm{Zn}\left(\mathrm{SO}_{4}\right)_{2} \cdot 4 \mathrm{H}_{2} \mathrm{O} \\
& \mathrm{Zn}^{2+}+2 \mathrm{e}^{-} \rightarrow \mathrm{Zn}
\end{aligned}
$$

\section{CONCLUSIONS}

In conclusion, we propose a novel symmetric zinc-ion hybrid supercapacitor, using hollow mesoporous-carbon nanospheres as electroactive materials and aqueous $\mathrm{ZnSO}_{4}$ as an electrolyte. The zinc-ion hybrid supercapacitor shows a high capacity of $212.5 \mathrm{~F} / \mathrm{g}$ at a current density of $0.2 \mathrm{~A} / \mathrm{g}$, a high energy density 
of $75.4 \mathrm{Wh} / \mathrm{kg}$ at a power density of $0.16 \mathrm{~kW} / \mathrm{kg}$, a good rate performance $(34.2 \mathrm{Wh} / \mathrm{kg}$ at high power of $16.0 \mathrm{~kW} / \mathrm{kg})$, and remarkable cycling stability $(99.4 \%$ of the capacity maintained after 2,500 charge/discharge cycles at $2 \mathrm{~A} / \mathrm{g}$ ). This high performance originates from the use of an open carbon structure, which offers a 3-dimensional surface molecular accessibility for reversible ion adsorption/desorption on the cathode and anode, as well as additional $\mathrm{Zn} / \mathrm{Zn}^{2+}$ deposition/stripping of the anode. We believe that the high performance of zinc-ion hybrid supercapacitor presented here, will be taken forward into the next-generation of energy storage devices.

\section{DATA AVAILABILITY STATEMENT}

The raw data supporting the conclusions of this article will be made available by the authors, without undue reservation.

\section{AUTHOR CONTRIBUTIONS}

SC, GY, and XZ design and carry out the major experiments and offer original experimental data. SC wrote the manuscript. GY carried out experiments, data analysis, and manuscript revision for peer-reviewing steps. NW, TW, SJ, SQ, TLi, and LD aided the experiments and contribute to the schematic drawing. $\mathrm{TLu}, \mathrm{JZ}$, and HaoW perform the analysis with constructive

\section{REFERENCES}

Bitenc, J., and Dominko, R. (2018). Opportunities and challenges in the development of cathode materials for rechargeable $\mathrm{Mg}$ batteries. Front. Chem. 6:634. doi: 10.3389/fchem.2018.00634

Chen, M., Chen, J., Zhou, W., Xu, J., and Wong, C. (2019a). High-performance flexible and self-healable quasi-solid-state zinc-ion hybrid supercapacitor based on borax-crosslinked polyvinyl alcohol/nanocellulose hydrogel electrolyte. J. Mater. Chem. 7, 26524-26532. doi: 10.1039/C9TA10944G

Chen, S. M., Ma, L. T., Zhang, K., Kamruzzaman, M., Zhi, C. Y., and Zapien, J. A. (2019b). A flexible solid-state zinc ion hybrid supercapacitor based on co-polymer derived hollow carbon spheres. J. Mater. Chem. A 7, 7784-7790. doi: 10.1039/C9TA00733D

Chen, X., Chen, K., Wang, H., and Xue, D. (2014). Functionality of $\mathrm{Fe}\left(\mathrm{NO}_{3}\right)_{3}$ salts as both positive and negative pseudocapacitor electrodes in alkaline aqueous electrolyte. Electrochim. Acta 147, 216-224. doi: 10.1016/j.electacta.2014.08.132

Cui, J., Wu, X., Yang, S., Li, C., Tang, F., Chen, J., et al. (2018). Cryptomelane-type $\mathrm{KMn}_{8} \mathrm{O}_{16}$ as potential cathode material-for aqueous zinc ion battery. Front. Chem. 6:352. doi: 10.3389/fchem.2018.00352

Dong, L., Ma, X., Li, Y., Zhao, L., Liu, W., Cheng, J., et al. (2018). Extremely safe, high-rate and ultralong-life zinc-ion hybrid supercapacitors. Energy Storage Mater. 13, 96-102. doi: 10.1016/j.ensm.2018.01.003

Fang, X., Zang, J., Wang, X., Zheng, M., and Zheng, N. (2014). A multiple coating route to hollow carbon spheres with foam-like shells and their applications in supercapacitor and confined catalysis. J. Mater. Chem. 2, 6191-6197. doi: $10.1039 / \mathrm{c} 3$ ta14881e

Gan, Y., Wang, C., Chen, X., Liang, P., Wan, H., Liu, X., et al. (2019). High conductivity $\mathrm{Ni}_{12} \mathrm{P}_{5}$ nanowires as high-rate electrode material for battery-supercapacitor hybrid devices. Chem. Eng. J. 392:123661. doi: 10.1016/j.cej.2019.123661

Liu, P., Gao, Y., Tan, Y., Liu, W., Huang, Y., Yan, J., et al. (2019a). Rational design of nitrogen doped hierarchical porous carbon for optimized zinc-ion hybrid supercapacitors. Nano Res. 12, 2835-2841. doi: 10.1007/s12274-019-2 521-6 discussions and play an important role in interpreting the results. XC and PA performed TEM characterization and TEM data analysis. XC takes a major part in designing the supercapacitor device configurations and writing the manuscript. HanW supervised the project, contributed to writing the paper, conceived and designed the supercapacitor materials and device, and analyzed all the experiment data. All authors contributed to the article and approved the submitted version.

\section{FUNDING}

This work was supported by the National Natural Science Foundation of China (No. 11574077), the Science and Technology Department of Hubei Province (No. 2019AAA038), and the Wuhan Yellow Crane Talent Program (No. 2017-02). This project received funding from the European Union's Horizon 2020 research and innovation programme under grant agreement No. 823717-ESTEEM3.

\section{SUPPLEMENTARY MATERIAL}

The Supplementary Material for this article can be found online at: https://www.frontiersin.org/articles/10.3389/fchem. 2020.00663/full\#supplementary-material
Liu, P., Ling, X., Zhong, C., Deng, Y., Han, X., and Hu, W. (2019b). Porous Zinc anode design for Zn-air chemistry. Front. Chem. 7:656. doi: 10.3389/fchem.2019.00656

Ma, L., Chen, S., Li, H., Zhaoheng, R., Tang, Z., Liu, Z., et al. (2018). Initiating a mild aqueous electrolyte $\mathrm{Co}_{3} \mathrm{O}_{4} / \mathrm{Zn}$ battery with $2.2 \mathrm{~V}$-high voltage and 5000cycle lifespan by a Co(III) rich-electrode. Energ. Environ. Sci. 11, 2521-2530. doi: 10.1039/C8EE01415A

Ma, X., Cheng, J., Dong, L., Liu, W., Mou, J., Zhao, L., et al. (2019). Multivalent ion storage towards high-performance aqueous zinc-ion hybrid supercapacitors. Energy Storage Mater. 20, 335-342. doi: 10.1016/j.ensm.2018.10.020

Meng, W., Chen, W., Zhao, L., Huang, Y., Zhu, M., Huang, Y., et al. (2014) Porous $\mathrm{Fe}_{3} \mathrm{O}_{4}$ /carbon composite electrode material prepared from metalorganic framework template and effect of temperature on its capacitance. Nano Energy 8, 133-140. doi: 10.1016/j.nanoen.2014.06.007

Parveen, N., Ansari, M. O., Ansari, S. A., and Cho, M. H. (2016). Correction: simultaneous sulfur doping and exfoliation of graphene from graphite using an electrochemical method for supercapacitor electrode materials. J. Mater. Chem. A 4, 12668-12669. doi: 10.1039/C6TA90155G

Shen, L., Wang, Y., Lv, H., Chen, S., Van Aken, P. A., Wu, X., et al. (2018). Ultrathin $\mathrm{Ti}_{2} \mathrm{Nb}_{2} \mathrm{O}_{9}$ nanosheets with pseudocapacitive properties as superior anode for sodium-ion batteries. Adv. Mater. 30:1804378. doi: 10.1002/adma.201804378

Shen, L., Wang, Y., Wu, F., Moudrakovski, I. L., Van Aken, P. A., Maier, J., et al. (2019). Hierarchical metal sulfide/carbon spheres: a generalized synthesis and high sodium-storage performance. Angew. Chem. 58, 7238-7243. doi: 10.1002/anie.201901840

Shen, L., and Yu, Y. (2017). Greener and cheaper. Nat. Energy 2, 836-837. doi: 10.1038/s41560-017-0026-7

Sun, G., Xiao, Y., Lu, B., Jin, X., Yang, H., Dai, C., et al. (2020). Hybrid energy storage device: combination of Zinc-Ion supercapacitor and ZincAir battery in mild electrolyte. ACS Appl. Mater. Interf. 12, 7239-7248. doi: 10.1021/acsami.9b20629

Sun, G., Yang, H., Zhang, G., Gao, J., Jin, X., Zhao, Y., et al. (2018). A capacity recoverable zinc-ion micro-supercapacitor. Energ. Environ. Sci. 11, 3367-3374. doi: $10.1039 / \mathrm{C} 8 \mathrm{EE} 02567 \mathrm{C}$ 
Tan, Q., Chen, X., Wan, H., Zhang, B., Liu, X., Li, L., et al. (2020). Metalorganic framework-derived high conductivity $\mathrm{Fe}_{3} \mathrm{C}$ with porous carbon on graphene as advanced anode materials for aqueous battery-supercapacitor hybrid devices. J. Power Sources 448:227403. doi: 10.1016/j.jpowsour.2019.2 27403

Wan, F., Zhang, L., Wang, X., Bi, S., Niu, Z., and Chen, J. (2018). An aqueous rechargeable Zinc-organic battery with hybrid mechanism. Adv. Funct. Mater. 28:1804975. doi: 10.1002/adfm.201804975

Wang, H., Wang, M., and Tang, Y. (2018). A novel zinc-ion hybrid supercapacitor for long-life and low-cost energy storage applications. Energy Storage Mater. 13, 1-7. doi: 10.1016/j.ensm.2017.12.022

Wang, Q., Wang, S., Guo, X., Ruan, L., Wei, N., Ma, Y., et al. (2019). MXene-reduced graphene oxide aerogel for aqueous Zinc-Ion hybrid supercapacitor with ultralong cycle life. Adv. Electron. Mater. 5:1900537. doi: 10.1002/aelm.201900537

Wei, C., Ru, Q., Kang, X., Hou, H., Cheng, C., and Zhang, D. (2018a). Self-template synthesis of double shelled ZnS-NiS1.97 hollow spheres for electrochemical energy storage. Appl. Surf. Sci. 435, 993-1001. doi: 10.1016/j.apsusc.2017.11.187

Wei, C., Zhan, N., Tao, J., Pang, S., Zhang, L., Cheng, C., et al. (2018b). Synthesis of hierarchically porous $\mathrm{NiCo}_{2} \mathrm{~S}_{4}$ core-shell hollow spheres via self-template route for high performance supercapacitors. Appl. Surf. Sci. 453, 288-296. doi: 10.1016/j.apsusc.2018.05.003

Wei, C., Zhang, R., Zheng, X., Ru, Q., Chen, Q., Cui, C., et al. (2018c). Hierarchical porous $\mathrm{NiCo}_{2} \mathrm{O}_{4} / \mathrm{CeO}_{2}$ hybrid materials for high performance supercapacitors. Inorg. Chem. Front. 5, 3126-3134. doi: 10.1039/C8QI01010B

Yan, Y., Zhang, F., Meng, Y., Tu, B., and Zhao, D. (2007). One-step synthesis of ordered mesoporous carbonaceous spheres by an aerosol-assisted selfassembly. Chem. Commun. 27, 2867-2869. doi: 10.1039/b702232h

Yu, F., Zhang, C., Wang, F., Gu, Y., Zhang, P., Waclawik, E. R., et al. (2020). A zinc bromine "supercapattery" system combining triple functions of capacitive, pseudocapacitive and battery-type charge storage. Mater. Horiz. 7, 495-503. doi: 10.1039/C9MH01353A

Yu, P., Zeng, Y., Zeng, Y., Dong, H., Hu, H., Liu, Y., et al. (2019). Achieving highenergy-density and ultra-stable zinc-ion hybrid supercapacitors by engineering hierarchical porous carbon architecture. Electrochim. Acta 327:134999. doi: 10.1016/j.electacta.2019.134999

Zhan, Y., Zhang, W., Lei, B., Liu, H., and Li, W. (2020). Recent development of Mg ion solid electrolyte. Front. Chem. 8:125. doi: 10.3389/fchem.2020.00125

Zhang, P., Li, Y., Wang, G., Wang, F., Yang, S., Zhu, F., et al. (2019). ZnIon hybrid micro-supercapacitors with ultrahigh areal energy density and long-term durability. Adv. Mater. 31:1806005. doi: 10.1002/adma.201806005

Zhang, Y., Yuan, C., Ye, K., Jiang, X., Yin, J., Wang, G., et al. (2014). An aqueous capacitor battery hybrid device based on Na-ion insertiondeinsertion in $\lambda-\mathrm{MnO}_{2}$ positive electrode. Electrochim. Acta 148, 237-243. doi: 10.1016/j.electacta.2014.10.052

Zuo, W., Li, R., Zhou, C., Li, Y., Xia, J., and Liu, J. (2017). Battery-supercapacitor hybrid devices: recent progress and future prospects. Adv. Sci. 4:1600539. doi: 10.1002/advs.201600539

Conflict of Interest: The authors declare that the research was conducted in the absence of any commercial or financial relationships that could be construed as a potential conflict of interest.

Copyright (C) 2020 Chen, Yang, Zhao, Wang, Luo, Chen, Wu, Jiang, van Aken, Qu, $\mathrm{Li}, \mathrm{Du}$, Zhang, Wang and Wang. This is an open-access article distributed under the terms of the Creative Commons Attribution License (CC BY). The use, distribution or reproduction in other forums is permitted, provided the original author(s) and the copyright owner(s) are credited and that the original publication in this journal is cited, in accordance with accepted academic practice. No use, distribution or reproduction is permitted which does not comply with these terms. 